\title{
Investigation of the Abrasive Lapping Process of Oxide Ceramics
}

\section{ALMAZ MULLAYANOVICH KHANOV, KARIM RAVILEVICH MURATOV and EVGENIY ANATOLYEVICH GASHEV}

\author{
Perm national Research Polytechnic University \\ 29 Komsomolsky prospect, Building A, Office109, Perm, Postcode 614990. \\ *Corresponding author E-mail: mtrushin@mail.ru
}

http://dx.doi.org/10.13005/ojc/320144

(Received: January 14, 2015; Accepted: March 15, 2016)

\begin{abstract}
In this paper the methods of ceramic materials treatments are summarized. For the treatment of a technical ceramics the grinding and finishing processes including the description of the treatment steps are reported. In the first step, up to $80 \%$ of the material is polished away and the grinding is carried out at increased velocities using a tool with larger grains. In the second step of grinding, the amount of the removed material is decreased and this step is carried out using the abrasive tool with smaller grains. The third step referred as finishing is done by diamond abrasive micro-powders and a paste with a certain grain size. Often, after this step the polishing is performed in order to achieve the precision class of 1-3 and low surface roughness. The abrasive finishing of the materials based on the oxide ceramics VSH-75 is investigated. It is found that the performance ability of the diamond micro-powder is higher by a factor of 15-30 compared to the electrocorundum and green silicon carbide micro-powders. By increasing the graininess, the amount of removed material and the roughness of a treated surface are increased. In order to achieve the $R z=0.8 \mu \mathrm{m}$ it is recommended to use a synthetic diamond micro-powder ASM20. Additionally, the influence of the contact pressure of the part onto the lap in the range from 25 to $150 \mathrm{kPa}$ is investigated. With the increase of the contact pressure from 25 to $50 \mathrm{kPa}$, the total removal is significantly increasing whereas the relative diamond micro-powder consumption and surface roughness are essentially decreasing. Further increase of the contact pressure up to $150 \mathrm{kPa}$ has smaller effect on the process parameters, while the cracks appear at the tool surface deteriorating the external view of the tool. The optimal contact pressure during finishing of the ceramic using the cast iron lap $\mathrm{SCH}-28$ is about $50-100 \mathrm{kPa}$
\end{abstract}

Key words: Technical Ceramics, Abrasive Finishing, Surface Finishing, Total Material Removal.

\section{INTRODUCTION}

Ceramics is polycrystalline materials and products composed of the compounds of non- metals of III-VI groups of periodic table and metals. Ceramics is obtained by forming and firing of the source material. The naturally occurring compounds such as silicates, clays and quartz as well as the 
artificial substances (pure oxides, carbides, nitrides, etc.) can be used as a source material. (Matrenin S.V. 2004 , Maslennikovoi G.N. 1991).

In mechanical engineering industry the technical ceramics is used for the production of structural high temperature and fire resistant parts such as cases, crucibles, gears, turbine blades. Additionally, a technical ceramics is used in instrumentation and chemical industries for the manufacturing of cutting tool plates, fillers and parts working in the aggressive environment (Kremen Z.I. 1984, Shevchenko V.Ya. 1993, Belyakov A.V. 1988, Garshin A.P. 1997).

A mechanical treatment of ceramics is a laborious and complex process aiming at achieving of parts with a required precision and quality of a surface. The mechanical treatment of ceramics can be performed by different methods:

$\begin{array}{ll}\text { 1. } & \text { Abrasive finishing } \\ \text { 2. } & \text { Electrical discharge and electro-chemical } \\ \text { machining } \\ \text { 3. } & \text { Ultrasociation } \\ \text { 4. } & \text { Hydrodynamic treatment } \\ \text { 5. } & \text { Laser cutting }\end{array}$

The most common type of mechanical treatment of ceramics is grinding and finishing (Breev B.T. 1982, Antyufeeva T.P. 1999).

Different abrasive materials such as natural and artificial corundum, silicon and boron carbides are used for the grinding and finishing of ceramics. The application of diamond polishing is advisable for the treatment of germanium, silicon, glass, quartz and solid alloys. The feature of the diamond polishing is a low wearing and high durability of the tool. According to the data of Japanese researchers, the cost of the ceramics polishing is ten times higher compared to the cost of the structural steel finishing (A.P. Garshin 2003, J. Kang, 2005, Jeong-Du Kim, 1995).

The mechanical treatment of ceramics depends on its properties such as hardness, brittleness, strength, porosity, surface state, thermal stability and properties of an abrasive material and the tool. It is also depends on the ceramics removal velocity, clamping force, cooling of the polishing material and other treatment conditions. Generally, the mechanical abrasive finishing of ceramics is performed in three steps: rough, clean and finishing operations. The reported steps differ by an amount of the removed ceramics and surface roughness, as shown in Table 1 (Balkevich V.L. 1984).

In the first step, roughening, up to $80 \%$ of the material is polished away and the grinding is carried out at increased velocities using a tool with larger grains. As a result, deep cracks and damages are presented on the surface. The rough tolerance of the size of part can reach 0.3-0.5 mm and it can be one- or double-side depending on the size of parts. In the second step of grinding, the amount of the removed material is decreased and this step is carried out using the abrasive tool with smaller grains. The third step, the finishing to the nominal size, is generally performed by diamond abrasive micro-powders and a paste with a certain grain size. Often, after this step the polishing is performed in order to achieve the precision class of 1-3 and low surface roughness.

At different steps of grinding, the type of surface cracks of ceramics is varying. Thus, the brittle damaging prevails during the diamond roughing. Two types of brittle damages can be observed. The first type is a cracking induced by clamping forces of

Table 1: Steps of abrasive finishing of ceramics

\begin{tabular}{lccc}
\hline Step & $\begin{array}{c}\text { Rough } \\
\text { tolerance, } \boldsymbol{\mu m}\end{array}$ & $\begin{array}{c}\text { Allowed } \\
\text { deviation of profile, } \boldsymbol{\mu m}\end{array}$ & $\begin{array}{c}\text { Surface roughness Rz, } \\
\boldsymbol{\mu m}\end{array}$ \\
\hline Roughening & 300 & $\pm(5-50)$ & $6,3-1,6$ \\
Clean polishing & $50-100$ & $\pm(3-20)$ & $1,6-0,8$ \\
Finishing & $3-10$ & $\pm(1-3)$ & $0,8-0,032$ \\
\hline
\end{tabular}


the abrasive tool. The second type is a detachment (flaking) of separated crystals (grains) from the binding phase due to tangential forces induced by relative movement of ceramics and abrasive.

Under the influence of these forces a partial abrasion of diamond occurs and a spalling or blunting of its facets can be observed. After roughening, the defects such as scratches or spalling could remain on the surface. The number of these defects depends on the size, shape and properties of diamond grains. During the clean polishing, the abrasive tool with lower graininess is used and, as a result, the brittle cracking is decreasing and the abrading effect and plastic deformation are dominating. The surface of ceramics is flattening. The finishing process is generally carried out using the diamond or abrasive micro-powders and paste with low graininess with domination of the abrading effect. The surface is finished to the precision class of 1-4 (Baharev B.P. 2009, Vakser D.B.. 1986).

Hence, the mechanical treatment of ceramic parts by using grinding is a complex process depending on the properties of ceramics, grinding apparatus, parameters of the polishing and other factors. In present work the finishing of the ceramic samples of the brand VSH-75 (HRC 90-93) is studied. The hardness, thermal stability and wear resistance of this material is transcendent compared to hard alloys. The considered disadvantage

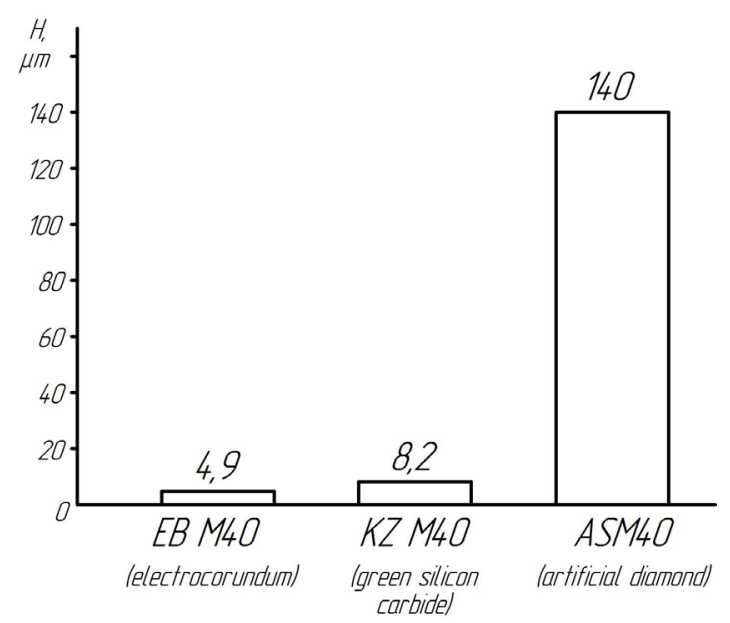

a) The total material removal $(\mathrm{H}, \mu \mathrm{m})$ of ceramics VSH-75 is a low strength and high brittleness. The machines equipped with plates made from ceramics VSH-75, are not loosing their hardness even after heating up to $1200^{\circ} \tilde{N}$ during the processing. Therefore they can be used in the unstressed conditions of the clean and half-clean polishing for the treatment of cast iron and steel parts, nonferous metals and their alloys when high velocities and temperatures are required.

\section{MATERIALS AND METHODS}

The lapping machine "Rastr 220" was used for all finishing experiments. The machine is dedicated for the finishing of various mechanical parts with precise flat surfaces. This table-top machine consists of three main parts : transmission block, press tool and a control panel with a frequency converter.

The micro-powders of electrocorundum white, silicon carbide green and artificial diamond were used as the abrasive materials. The graininess of diamond was varied in the range from 40 to $5 \mu \mathrm{m}$ and is reported for each condition in the sample description. The abrasive material was homogenously deposited on the lap surface by a filler method.

Regardless the nature of abrasive material, its volume was set to $50 \mathrm{~cm}^{3}$ for all experiments. This volume provides the deposition of single layer

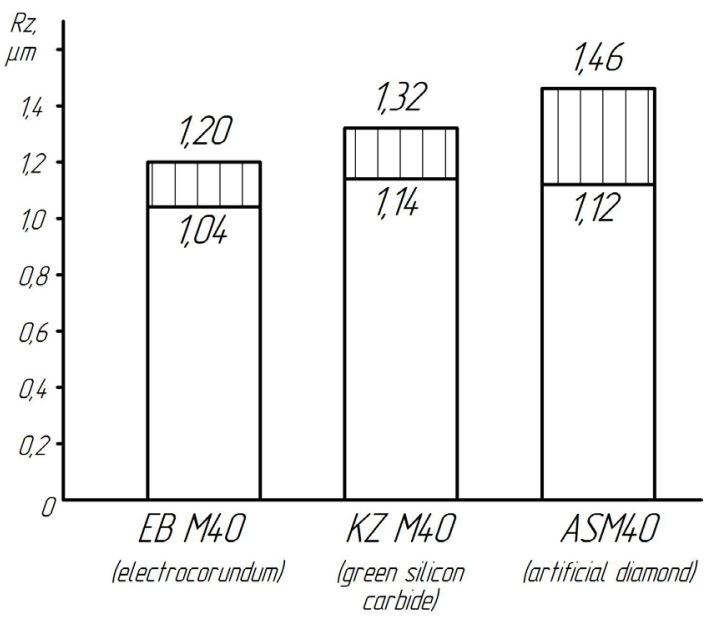

b) The roughness of treated surface $R z, \mu m$

Fig. 1: The comparative study of the abrasive materials for the finishing of oxide ceramics VSH-75, the treatment time $T=4 \mathrm{~min}$ 
of grains on the surface of the lap with a diameter of $220 \mathrm{~mm}$. The weight of each micro-powder was calculated based on the volume and specific weight :

$$
\begin{array}{ll}
\text { - } & \text { Electrocorundum white - } 200 \mathrm{mg} \text {; } \\
\text { - } & \text { Silicon carbide green - } 160 \mathrm{mg} ; \\
& \text { Artificial diamond - } 175 \mathrm{mg} .
\end{array}
$$

The mixture of kerosene (70\%), oil 120 (25\%) and oleinic acid (5\%) was used as a liquid environment. This mixture was dropped on the lap surface in the volume of $0.75-1 \mathrm{~cm}^{3} \mathrm{p}$

\section{RESULTS}

The complex investigations of the abrasive finishing of parts prepared from ceramics VSH75 (HRC 90-95) was done by lapping machine with scanning tool trajectory (Khanov A. M. 2010, Antsiferov V.N.. 2011, Nekrasov V.P. 2006, Khanov

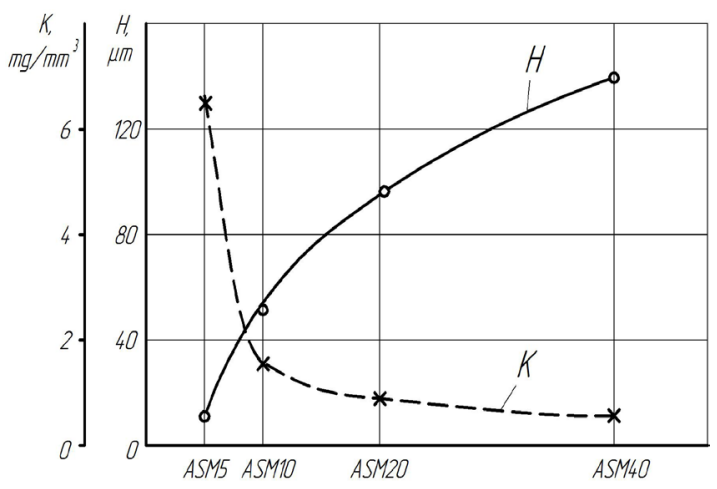

a) The specific consumption of diamonds
A.. 2010). The material of tool (lap) was a pearlite cast iron $\mathrm{SCH} 28$. The required surface roughness $\mathrm{Rz}$ (Tebenkin A.N. 2007) was less than $0.9 \mu \mathrm{m}$.

It is known that the properties of the abrasive micro-powder used for finishing significantly affect the results of the treatment. (Kremen Z.I. 2007). This effect is even more pronounced during the finishing of hard materials such as ceramics. This was confirmed by the comparative study of the efficiency of several types of micro-powders including white electrocorundum EB M40, green silicon carbide KZ M40 and artificial diamond ASM40 for the finishing process using the cast iron lap. The efficiency of the artificial diamond micro-powder ASM40 evaluated by measuring the total material removal $(\mathrm{H}, \mu \mathrm{m})$ per 4 minutes of treatment is higher by a factor of 15-30 compared to the efficiency of EB M40 and KZ M40 (Figure 1 à). It can be explained by the fact that the hardness of treated material is only slightly

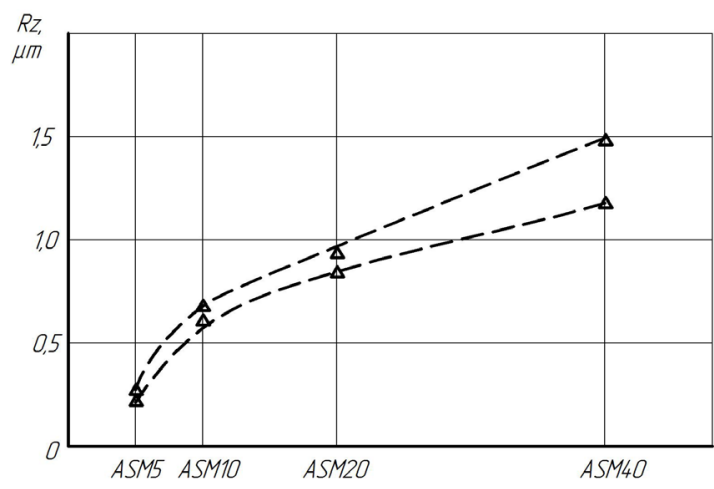

b) The roughness of treated surface $R z, \mu m$ $(\mathrm{Kg} / \mathrm{mm} 3)$ and the total material removal $(\mathrm{H} \mu \mathrm{m})$

Fig. 2: The comparative study of the influence of the diamond micro-powder graininess on the finishing of ceramics

lower compared to the micro-powders EB M40 and $\mathrm{KZ}$ M40, whereas the hardness of the artificial diamond micro-powder ASM40is significantly higher compared to ceramics. The roughness of treated surface was not practically influenced by the type of abrasive material and it was changing with the error margin (Figure 1b).

By taking into account the extremely high efficiency of the artificial diamond micro-powder, it is clear that this abrasive material is preferable for the finishing of hard materials such as oxide ceramics. The size and amount of working diamond grains depends with the graininess of the micropowder if other conditions are kept constant. Thus, the changes of the powder graininess influence the micro-cutting process and affect the finishing efficiency, specific consumption of diamond micropowder $\left(\mathrm{K} \mathrm{mg} / \mathrm{mm}^{3}\right)$ and the roughness of treated surface. The investigation of the oxide ceramics VSH-75 finishing using diamond micro-powders with different graininess revealed that the total material 
removal was increasing with the increase of the micro-powder graininess from ASM5 to ASM40 (Figure 2a). This effect is related to the fact that with increasing of diamond grains size their total amount was decreasing and it led to the increased pressure applied to each grain. Therefore, grains are deeper penetrating inside the material and cutting the micro-shavings with bigger size. With the graininess increase the relative specific consumption of diamonds was decreasing and the decrease was more intense when comparing ASM5 and ASM10 (Figure 2a). With the increase of diamond micro-powder graininess from ASM5 to ASM40, the roughness of treated surface was increasing from $R z=0.27$ to $1.14 \mu \mathrm{m}$ (Figure $2 b$ ). However, by increasing the amount of micro-powder from 100 to $175 \mathrm{mg}$, the total removal was increasing very slightly (from 93 to $97 \mu \mathrm{m}$ ), whereas the relative specific consumption of diamonds increased by a factor of 1.6 (from 0.52 to $0.85 \mathrm{mg} / \mathrm{cm}^{3}$ ).

The roughness of the treated surface does not practically depend on the amount of the micropowder and lies in a narrow range of $R z=0.78-1.0$ $\mu \mathrm{m}$. Additionally, it was revealed that the variation of the amount of micro-powder with this range does not significantly affect the density of the treated surface. Similar results were obtained for the investigation of the micro-powder ASM10 (Figure 4).

By taking into account that the finishing using the micro-powder ASM20 provided essentially high efficiency, mild specific consumption of diamonds and the obtained surface roughness was quite low $R z=0.7-0.8 \mu \mathrm{m}$, all further investigations were performed with this type of micro-powder.

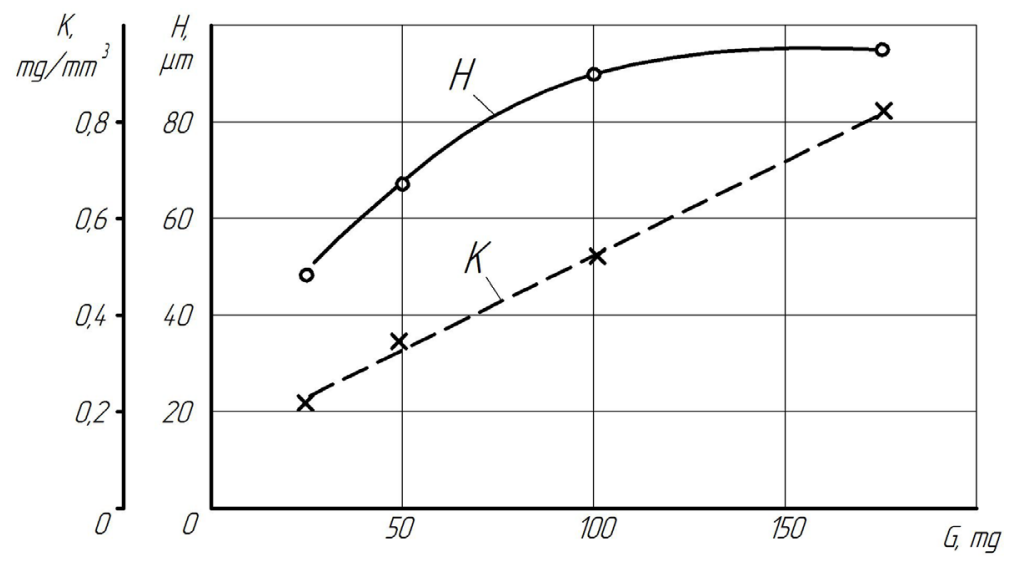

Fig. 3: The dependence of total removal $\mathrm{H}$ and specific consumption of diamonds $\mathrm{K}$ as a function of the amount of diamond micro-powder ${ }_{\text {от }}$ ASM20

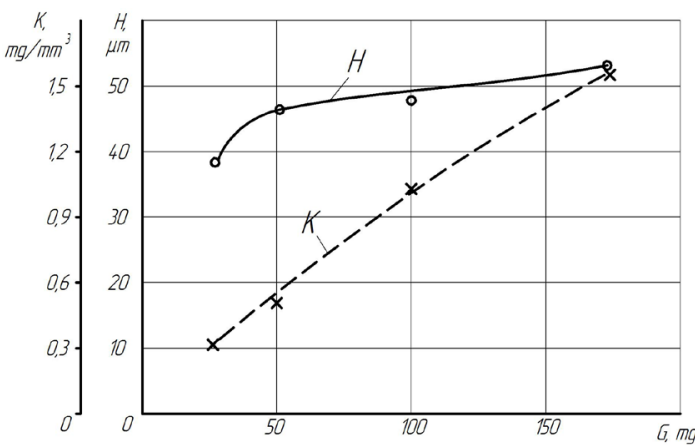

a) The specific consumption of diamonds $(K \mathrm{mg} /$ $\mathrm{mm} 3)$ and total removal of material $(H \mu \mathrm{m})$

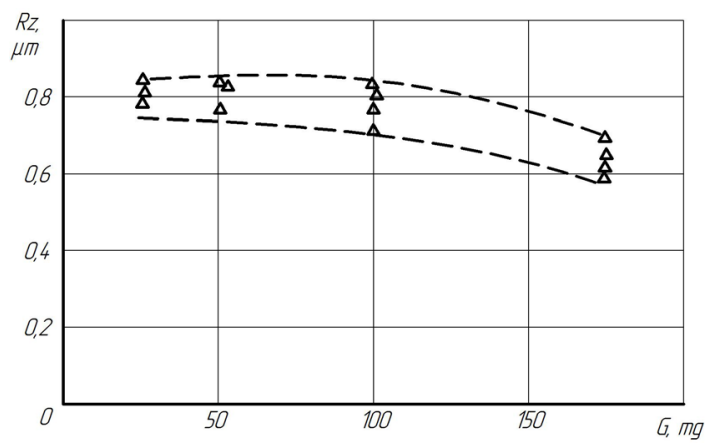

b) The surface roughness $\mathrm{Rz}, \mu \mathrm{m}$

Fig. 4: The comparative investigation of the influence of the amount of the diamond micro-powder ACM10 on the parameters of the finishing process 


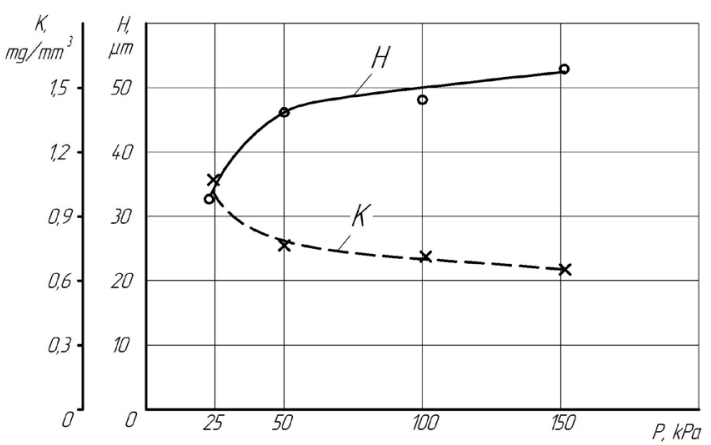

a) The specific consumption of diamonds (Kmg/ $\mathrm{mm} 3)$ and the total material removal $(\mathrm{H} \mu \mathrm{m})$

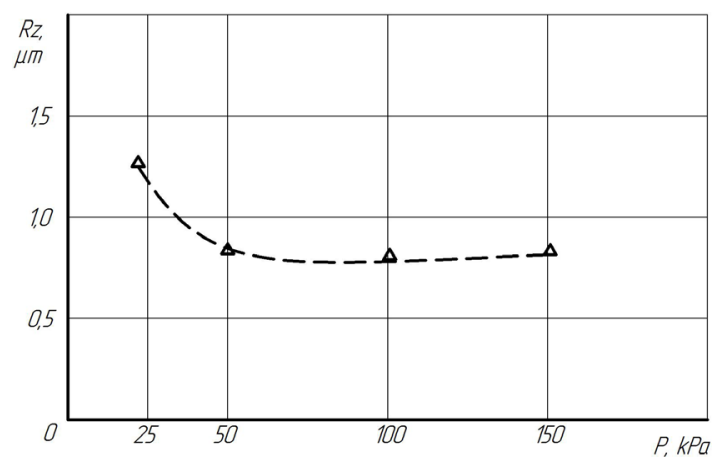

b) The roughness of treated surface $R z, \mu \mathrm{m}$

Fig. 5: The comparative investigation of the influence of the contact pressure during the finishing of ceramics by diamond micro-powder ACM20

The amount of the diamond micro-powder added on the lap surface affect the finishing performance and, first of all, the specific consumption of diamonds $K$ and process efficiency $H$. During the experiments with metal-ceramics, the amount of the diamond micro-powder ASM20 placed on the surface of cast iron lap was varied in the range from, 50 to $175 \mathrm{mg}$ (from $14 \pi 050 \mathrm{~cm}^{3}$ ).

It was found that with increasing amount of diamond micro-powder both relative specific consumption of diamonds and the total removal of materials were increasing as shown in Figure 3.

It is worth noting that the increase of the amount of micro-powder ASM10 from 50 to $175 \mathrm{mg}$ led to the slight increase of the total removal, whereas the specific consumption of diamonds was increasing by a factor of 3 (from $0.51 \pi 0$ to $1.57 \mathrm{mg} / \mathrm{cm}^{3}$ ).

For the finishing of metal-ceramics parts using the iron cast lap CHS-28 with a diameter of 220 $\mathrm{mm}$, the optimal amount of diamond micro-powder was about 20-45 and 40-80 mg, for graininess ASM10 and ASM20, respectively.

The contact pressure between parts and lap is delivered through the diamond grains. This pressure determines the lead on each working grain and affects the condition of micro-cutting. The influence of contact pressure during the finishing of ceramics by the ASM20 was studied in the range from 25 to $150 \mathrm{kPa}$. It was revealed that the value of the total removal í is increasing with the increase of the contact pressure from 25 to $50 \mathrm{kPa}$ and slightly varying with further increase up to $150 \mathrm{kPa}$ (Figure 5a).

This latter can be explained by an intensive refinement of diamond micro-powder grains induced by a high load. The specific consumption of diamonds (K) was decreasing with contact pressure and the most significant decrease was in the range from 25 to $50 \mathrm{kPa}$ (Figure 5a).

The roughness of a treated surface $R z$ was decreased from 1.28 äî $0.70 \mu \mathrm{m}$ when the contact pressure increased from 25 to $50 \mathrm{kPa}$. Further increase of the pressure up to $150 \mathrm{kPa}$ did not practically induce variation of the roughness as shown in Figure 5b. This latter confirmed the hypothesis of the intensive refinement of diamond grains at an elevated contact pressure. It is worth noting that after finishing at $150 \mathrm{kPa}$, the surface of cast iron lap CHS-28 exhibited cracks deteriorating an external view of the tool. Hence, an optimal contact pressure for the finishing of ceramics using cast iron lap is about $50-100 \mathrm{kPa}$.

\section{CONCLUSIONS}

The graininess of artificial diamond micro-powders significantly influences the finishing efficiency and a roughness of a treated surface. With an increase of the graininess the total removal of the material and surface roughness are increasing. In 
order to achieve the required roughness $\mathrm{Rz}=0.9 \mu \mathrm{m}$ and sufficient process efficiency it is recommended to use artificial diamond micro-powder ASM20.

The contact pressure between the lap and a part is also affecting the finishing process. The increase of the contact pressure from 25 to $50 \mathrm{kPa}$ induces the significant increase of the total removal accompanied with the decrease of the specific consumption of diamonds and surface roughness. However, further increase of the contact pressure up to $150 \mathrm{kPa}$ has smaller effect on the finishing results. An optimal contact pressure for the finishing of ceramics using the cast iron lap CHS-28 is about $50-100 \mathrm{kPa}$.
On the basis of the obtained results, the investigation of the machine working in a "scanning" trajectory regime will be performed. The influence of multiple parameters including the amplitude and frequency of the vibrations on the quantitative parameters of the treated surface of ceramics will be studied.

\section{ACKNOWLEDGEMENT}

Financial support was provided by the Russian Ministry of Education and Science on the state assignment (project part) no. 9.1570.2014/K

\section{REFERENCES}

1. Antyufeeva T.P. Some dependencies of finishing of parts prepared from technical ceramics / T.P. Antyufeeva, V.P. Baharev, G.A. Smirnov,- Technology of automation and organization of production of technical systems. Mezhvuzov. Obz. Nuach. Trudov, M. , MGIU, 1999.

2. Antsiferov V.N., Khanov A.M., Muratov, K.P.,Muratov, R.A., Scanning method of the treatment of precision surfaces. // Izvestia Samarskogo Nauchnogo centra Rossiyskoi Academii Nauk. - 2011.- 13., 1.,512-519

3. Balkevich V.L. Tecjnical ceramics / V.L. Balkevich. - İ.: Stroiizdat, 1984. - 256.

4. Baharev V.P. The basics of planning and control of processes of finishing of ceramic and composite materials. N.P. Baharev.Ivanovo, IVGU, 2009,.7,10-50,190-198.

5. Belyakov A.V. Technology of ceramics for mechanical engineering / A.V. Belyakov.VINITI, 1988,- V. 1.- pp. 3-71.

6. Breev B.T.The modernization of machines for fast / B.T. Breev. -Ì., Mashinostroenie, 1982. $60 \mathrm{p}$.

7. Vakser D.B. Diamond treatment of technical ceramics /D.B. Vakser, V.A IvanovÂ.À.- L.: Mashinostroenie, 1986. pp.34-59.

8. Garshin A.P.. Ceramics for mechanical engineering/ A.P. Garshin, V.M. Gropyanov, G.P/ Zaytsev, S.S. Semenov. - M.: OOO Inzdatelstvo Nauchtekhlitizdat, 2003. - 384

\section{p.}

9. Garshing A.P. Mechanical engineering ceramics/A.P. Garshin, V.M. Gropyanov, G.P/ Zaytsev, S.S. Semenov / SPb: izdatelstvo SPbGTU, 1997, pp.722-726.

10. Kremen Z.I..Fast diamond treatment of parts from technical ceramics /Z.I. Kremen - L.: Mashinostroenie, 1984.- 131p.

11. Kremen Z.I. Technology of polishing in mechanical engineering / Z.I. Kremen, V.G. Yur'ev, A.F. Baboshkin. - St. Petersburg: Politekhnika, 2007. - 424 p.

12. Maslenikovoi G.N. Ceramic materials / G.N. Maslenikovoi.- M.: Stroiizdat, 1991.-214p.

13. Matrenin S.V. Technical ceramics: Handbook / S.V. Matrenin, A.I. Slosman - Tomsk.: TPU, 2004. - $75 \mathrm{p}$.

14. Nekrasov V.P., Muratov R.A. Machines with scanning kinematics for finishing of surfaces with constant curvature. Modern organizational, technological and construction methods of quality control. Proceedings. Perm: PGTU, 2006. - pp. 96 - 116.

15. Tebenkin A.N. Roughness, waviness, profile. International experience/ A.N. Tebenkin, S.B. Tarasov, S.N. Stepanov - St. Petersburg: Publisher of Politechnical University, 2007. $136 \mathrm{p}$.

16. Khanov A. M., Muratov R.A., Muratov K.R. , Gashev E.A. Technology and equipment with scanning kinematics for the formation 
of surface roughness of constant curvature in nanometer range // STIN. - 2010. №2 pp. 34-35.

17. Shevchenko V.Ya. Introduction to the rechnical ceramics / V.Ya. Shevchenko. - M..: Nauka, 1993.- $112 p$.

18. Jeong-Du Kim, Min-Seog Choi. A study on the optimization of the cylindrical lapping process for engineering fine-ceramics (Al2O3) by the statistical design method. // Journal of Materials Processing Technology. 1995.Vol.
52, pp. 368-385.

19. Kang J., Hadfield M. Examination of the material removal mechanisms during the lapping process of advanced ceramic rolling elements. // Original Research Article. 2005. Vol. 258, pp. 2-12.

20. Khanov A.M., Muratov R.A., Muratov K.R., Gashev E.A. Nanoroughness produced by systems with raster kinematics on surfaces of constant curvature.// Russian Engineering Research. 2010. Ò. 30. no 5. pp. 528-529. 